\title{
Lifestyle and Body Weight Consequences of the COVID-19 Pandemic in Children: Increasing Disparity
}

\author{
Berthold Koletzko $^{\text {a }}$ Christina Holzapfel $^{b} \quad$ Ulrike Schneider $^{c}$ Hans Hauner $^{b}$ \\ aDivision of Metabolic and Nutritional Medicine, Department of Paediatrics, Dr. von Hauner Children's Hospital, LMU \\ University Hospitals, LMU - Ludwig-Maximilians Universität Munich, Munich, Germany; ${ }^{\text {b}}$ TUM School of Medicine,

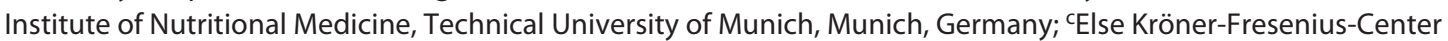 \\ of Nutritional Medicine, TUM School of Life Sciences, Technical University of Munich, Freising, Germany
}

Children get infected by SARS-CoV-2; however, compared to adults, they are far more likely to be asymptomatic shedders and have a relatively low risk of developing severe disease $[1,2]$. Therefore, it has been assumed that the COVID-19 pandemic would induce little adverse health effects in children. However, concern was been raised that the COVID-19 pandemic will most likely aggravate food shortages and undernutrition among children in low- and low-medium-income countries [3]. In contrast, an online survey including 1,097 adults in Poland reported a greater degree of snacking (52\%) and eating more $(43 \%)$ during the nationwide quarantine due to the COVID-19 pandemic [4]. Almost 30\% experienced weight gain, with a mean reported increase of $3 \mathrm{~kg}$, while over $18 \%$ reported a mean weight loss of $3 \mathrm{~kg}$.

Data are lacking on possible effects of the pandemic in children in high-income countries. We hypothesized that the consequences of the pandemic, such as social distancing and closure of educational institutions, will affect dietary practices and related health indicators in children and their families. To explore this question, we performed a representative survey on dietary practices and health issues among German families. We designed a questionnaire with 15 questions. The questionnaire was applied in

karger@karger.com

(c) 2021 S. Karger AG, Basel

www.karger.com/anm

Karger! an online survey performed by the Forsa Institute for Social Research and Statistical Analysis (forsa Politik- und Sozialforschung $\mathrm{GmbH}$, Berlin, Germany) during the time period of September 11-16, 2020. Standard questions on sociodemographic characteristics were included, but in order to keep the survey short, no information on migrant background was collected. Parents were advised to answer the questions in relation to the pandemic-induced changes during the preceding 6 months. During this time, the consequences of the pandemic in Germany included social distancing and reduced face-to-face meetings of people, a change to working in home office for many employees, and the at least partial closure of most day cares and schools and many sports facilities. Participants of this survey were 1,000 parents (age 20-65 years) with at least 1 child up to the age of 14 years living in the same household. The parents were selected with a systematic random method established by the Forsa Institute (forsa.ominet), considered to obtain a representative population sample.

Almost two-thirds (64\%) of the participating parents reported that they, or the other parent, or both, worked in home office, with equal proportions working (almost) fully or only partly in home office (Table 1). Working in 
Table 1. Prevalence of changes that occurred during the first 6 months of the COVID-19 pandemic reported by 1,000 parents with at least 1 child up to the age of 14 years living in the same household in Germany

\begin{tabular}{|c|c|c|c|c|c|c|}
\hline \multirow[t]{2}{*}{ Since the start of the COVID-19 pandemic } & \multirow[t]{2}{*}{ All } & \multicolumn{5}{|c|}{ Child age, yr } \\
\hline & & $0-2$ & $3-5$ & $6-9$ & $10-12$ & $13-14$ \\
\hline \multicolumn{7}{|l|}{ Parents and family } \\
\hline \multicolumn{7}{|l|}{ At least 1 parent worked in home office, $\%$} \\
\hline Almost all the time & 32 & 31 & 35 & 34 & 30 & 25 \\
\hline Part of the time & 32 & 32 & 34 & 32 & 29 & 36 \\
\hline Our family eats healthier, $\%$ & 14 & 15 & 12 & 16 & 10 & 14 \\
\hline Our family eats less healthy, \% & 7 & 6 & 8 & 7 & 9 & 5 \\
\hline We cooked more at home, $\%$ & 30 & 21 & 34 & 36 & 29 & 25 \\
\hline \multicolumn{7}{|l|}{ We used home delivery services for food, \% } \\
\hline More often & 8 & 6 & 7 & 12 & 6 & 6 \\
\hline Less often & 11 & 7 & 15 & 10 & 14 & 11 \\
\hline \multicolumn{7}{|l|}{ We used takeout foods, $\%$} \\
\hline More often & 10 & 7 & 8 & 13 & 8 & 11 \\
\hline Less often & 16 & 10 & 18 & 17 & 19 & 17 \\
\hline Weight gain of the parent & 27 & 24 & 20 & 20 & 30 & 27 \\
\hline \multicolumn{7}{|l|}{ Children, \% } \\
\hline My child gained weight & 9 & 3 & 2 & 10 & 21 & 9 \\
\hline My child's physical activity decreased & 38 & 12 & 28 & 41 & 50 & 57 \\
\hline \multicolumn{7}{|l|}{ My child increased consumption of, \% } \\
\hline Vegetables & 14 & 16 & 15 & 15 & 9 & 14 \\
\hline Fruits & 20 & 16 & 19 & 21 & 23 & 21 \\
\hline Potatoes, pasta, rice, pizza & 13 & 11 & 11 & 15 & 14 & 14 \\
\hline Salty snack foods & 18 & 10 & 12 & 17 & 27 & 24 \\
\hline Sweet snack foods & 20 & 16 & 19 & 21 & 23 & 21 \\
\hline Soft drinks & 18 & 3 & 6 & 12 & 15 & 19 \\
\hline
\end{tabular}

Numbers considered particularly relevant are printed in bold.

the home office was more common among parents with completed higher or university education $(79 \%)$ and those with high incomes ( $80 \%$ of those with a monthly family income of $>4,500 €$ ). The proportion of parents fully working in home office increased with the size of the community they lived in $20 \%$ in communities with $<5,000$ inhabitants, $35 \%$ with $20,000-100,000$, and $40 \%$ with $>500,000$ ), whereas the child's age was not consistently related to working in home office. Parents reported eating more often healthier diets (14\%) and cooking more at home for their child (30\%), with higher proportions among those who worked mostly in home office (20 and $43 \%$, respectively). About equal numbers near $10 \%$ reported an increase or decrease of using home delivery of foods or takeout foods, respectively (Table 1). Some $27 \%$ of parents reported having gained weight since the start of the pandemic, with equal proportions among mothers and fathers, and no clear association with income, community size, or child age.
An increase of children's body weight during the pandemic was reported by $9 \%$, with a much greater prevalence of $23 \%$ among children whose parents had a low level of school education ( $<10$ years). An increased body weight was hardly observed among preschool children, but it occurred mostly in school-age children, particularly in the age group of 10 - to 12 -year-olds (19\%; Table 1), with much more affected boys (24\%) than girls (13\%). A reduction of physical activity was reported for $38 \%$ of all children and for almost $60 \%$ of children aged 10 years and older (Table 1 ).

Reported changes in childrens' food habits included an increased consumption of vegetables in $14 \%$ and of fruits in $20 \%$, with no consistent relationship to childrens' age (Table 1), while intakes of meat and processed meats decreased by $13 \%$. These changes appeared to result from more home preparation of meals by parents working in home office (data not shown). At the same time, there was also an increase in the consumption of salty snacks (18\%), 
sweet snacks (20\%), and soft drinks (18\%), affecting clearly higher proportions of school-age children aged 10 years and older (Table 1). Boys were more likely than girls to show an increased consumption of salty snacks ( $20 \mathrm{vs.}$ $15 \%$ ), sweet snacks (22 vs. $17 \%$ ), and soft drinks (12 vs. $9 \%$ ), and potatoes, pasta, rice, and pizza (16 vs. $11 \%$ ).

These results show that the COVID-19 pandemic induces health effects that extend beyond the infection itself. Families that are more homebound due to social distancing or lockdown measures, working more from home, and reduced preschool and school attendance of their children may put more attention to the choice of foods and drinks and replace canteen and processed food by more home-cooked foods, particularly in more privileged families with higher education and income levels. At the same time, both potential increased boredom and psychosocial stress induced in parents and children, for example, due to having to combine work and childcare, the threat of job and income loss, and social isolation, may trigger increased reduced physical activity, potentially increased physically inactive screen time, and increased consumption of energy-dense snack foods and soft drinks and an increased weight gain and risk of overweight and obesity. Our data show a disturbing aggravation of socioeconomic disparity, with a 2.5 times higher risk of body weight gain in children from less privileged than from better educated families. The risk of weight gain, reduced physical activity, and less favourable food and beverage consumption habits is higher in schoolaged children aged 10 years and older than in younger children. More efforts are required to develop and evalu- ate support strategies that target such high-risk groups. Effective strategies should be widely implemented to prevent further long-term adverse effects of the pandemic.

\section{Acknowledgement}

We thank the staff of forsa Politik- und Sozialforschung GmbH, Berlin, Germany, for performing the survey.

\section{Conflict of Interest Statement}

The work of the authors has been financially supported in part by the Else Kröner-Fresensius Foundation, Bad Homburg, Germany. None of the authors declares a conflict of interest with respect to the content of this manuscript.

\section{Funding Sources}

The survey reported here was financially supported by the Else Kröner-Fresenius-Foundation, Bad Homburg, Germany. B.K. is the Else Kröner-Senior professor of Paediatrics at LMU co-funded by the Else Kröner-Fresenius Foundation and LMU University Hospitals.

\section{Author Contributions}

B.K. conceived the study; C.H., B.K., and H.H. designed the study questionnaire; all authors reviewed, analysed and interpreted the results; bk wrote the first draft of the manuscript; all authors reviewed and contributed to the revision of the manuscript.

\section{References}

1 Klein JD, Koletzko B, El-Shabrawi MH, Hadjipanayis A, Thacker N, Bhutta Z. Promoting and supporting children's health and healthcare during COVID-19: International Paediatric Association Position Statement. Arch Dis Child. 2020;105(7):620-4.

2 Dong Y, Mo X, Hu Y, Qi X, Jiang F, Jiang Z, et al. Epidemiology of COVID-19 among children in China. Pediatrics. 2020;145(6): e20200702.
3 Akseer N, Kandru G, Keats EC, Bhutta ZA. COVID-19 pandemic and mitigation strategies: implications for maternal and child health and nutrition. Am J Clin Nutr. 2020; 112(2):251-6.

4 Sidor A, Rzymski P. Dietary choices and habits during COVID-19 lockdown: experience from Poland. Nutrients. 2020;12(6):1657. 